DOI: http://dx.doi.org/10.33846/ghs6110

\title{
Hubungan Pengetahuan, Keadaan Sosial Ekonomi Dan Tindakan Dengan Penanganan Sampah Rumah Tangga Di RT 01/RW 05 Kelurahan Klabulu Kota Sorong
}

Febry Talakua (koresponden)

Program Studi Ilmu Kesehatan Masyarakat, Stikes Papua; febrytalakua01@gmail.com

\begin{abstract}
Garbage is one of the environmental problems that has long been a concern of the world and needs serious handling so as not to cause harmful impacts. The large pile of garbage will hurt health, the environment, and socio-economic. In Klabulu Village, some people use vacant land or roadside as a garbage dump. If household waste is not handled properly, during the rainy season the waste will be carried away by water and enter the ditch resulting in flooding. The purpose of the study was to determine the relationship between knowledge, socio-economic conditions, and actions for handling household waste in RT 01/RW 05, Klabulu Village, Sorong City. This type of research was quantitative with a cross-sectional study design. The research was conducted in RT 01/RW 05, Klabulu Village, Sorong City in July-August 2020. The population of the study was 50 families. The sample was the head of the family as many as 50 people taken by total sampling. The research instrument used was a questionnaire. Data were analyzed using the Chi-square test with a confidence level of 0.05 . The results showed that knowledge $p$-value $0.029<0.05$, socio-economic conditions $p$-value $0.036<0.05$ and $p$ value $0.000<0.05$. The study concludes that there is a relationship between knowledge, socioeconomic conditions, and actions with handling household waste in RT 01/RW 05, Klabulu Village, Sorong City.
\end{abstract}

Keywords: knowledge; socio-economic; action; waste handling

\section{ABSTRAK}

Sampah merupakan salah satu masalah lingkungan hidup yang sejak lama telah menjadi perhatian dunia dan perlu mendapat penanganan yang serius agar tidak menimbulkan dampak yang membahayakan. Banyaknya tumpukan sampah akan berdampak negatif pada kesehatan, lingkungan dan sosial ekonomi. Kelurahan Klabulu ada masyarakat menjadikan lahan kosong ataupun pinggiran jalan sebagai tempat pembuangan sampah. Jika sampah rumah tangga tidak ditangani dengan baik maka ketika musim hujan sampah akan terbawa air dan masuk ke dalam selokan mengakibatkan banjir. Tujuan penelitian adalah untuk mengetahui hubungan pengetahuan, keadaan sosial ekonomi dan tindakan penanganan sampah rumah tangga di RT 01/RW 05 Kelurahan Klabulu, Kota Sorong. Jenis penelitian adalah kuantitatif dengan rancangan cross sectional study. Penelitian dilakukan di RT 01/RW 05 Kelurahan Klabulu, Kota Sorong pada bulan Juli-Agustus tahun 2020. Populasi penelitian berjumlah $50 \mathrm{KK}$. Sampel adalah kepala keluarga sebanyak 50 orang yang diambil secara total sampling. Instrumen penelitian yang digunakan kuesioner. Data dianalisa menggunakan uji chi-square dengan tingkat kepercayaan 0,05. Hasil penelitian diperoleh bahwa pengetahuan $p$-value 0,029 $<0,05$, keadaan sosial ekonomi $p$-value $0,036<0,05$ dan tindakan $p$-value $0,000<0,05$. Kesimpulan penelitian adalah ada hubungan pengetahuan, keadaan sosial ekonomi dan tindakan dengan penanganan sampah rumah tangga di RT 01/RW 05 Kelurahan Klabulu Kota Sorong.

Kata kunci: pengetahuan; sosial ekonomi; tindakan; penanganan sampah

\section{PENDAHULUAN}

\section{Latar Belakang}

Dalam mencapai kondisi masyarakat yang hidup sehat dan sejahtera di masa yang akan datang sangat diperlukan adanya lingkungan pemukiman yang bersih dan sehat, karena persoalan lingkungan yang selalu menjadi isu besar hampir seluruh wilayah di dunia adalah sampah ${ }^{(1)}$. Sampah merupakan hasil dari aktivitas manusia yang keberadaannya tidak dapat dihindari dan harus dikelola dengan baik karena pengelolaan sampah yang tidak memenuhi syarat kesehatan dapat mengakibatkan terjadinya pencemaran lingkungan, kondisi ini mengakibatkan terjadinya penurunan kualitas lingkungan hidup dan gangguan pada kesehatan manusia(2). Akibat pesatnya pertumbuhan penduduk dunia dan pembangunan menjadikan sampah sebagai masalah yang komplek dan dihadapi oleh hampir seluruh 
bangsa $^{(3)}$. Timbulan sampah meningkat ketika negara dan kota mengalami urbanisasi, sehingga berkembang secara ekonomi dan bertambahnya jumlah penduduk ${ }^{(4)}$.

Indonesia menghasilkan sampah sekitar 66-67 juta ton sampah pada tahun 2019, jumlah ini lebih tinggi dibandingkan jumlah sampah per tahunnya yang mencapai 64 juta ton dan jenis sampah yang dihasilkan didominasi oleh sampah organik yang mencapai sekitar $60 \%$ dan sampah plastik yang mencapai $15 \%^{(5)}$. Kota Sorong menunjukkan bahwa Kota Sorong menghasilkan sampah sekitar 144 ton/hari pada tahun 2017 menunjukkan bahwa potensi sampah akan meningkat secara linear dengan peningkatan jumlah penduduk ${ }^{(6)}$.

Banyaknya tumpukan sampah akan berdampak negatif pada kesehatan, lingkungan, sosial ekonomi, pencemaran air, tanah dan udara yang akibat keberadaan sampah menurunkan kualitas lingkungan ${ }^{(7)}$. Sampah menjadi media penularan infeksi parasit, mengganggu estetika lingkungan, bahkan dapat menyebabkan bencana banjir bila dibuang ke badan air, dan sampah yang tidak ditangani dengan baik akan berkonsekuensi pada mahalnya biaya pengelolaan lingkungan serta kerugian secara ekonomi berupa terhambatnya perkembangan sektor pariwisata, terhambatnya perkembangan otonomi daerah serta mengurangi arus investor ${ }^{(8)}$.

Kelurahan Klabulu merupakan salah satu kelurahan yang tergolong daerah yang memiliki masyarakat dengan keadaan sosial ekonomi cukup beragam. Ada beberapa rumah di Kelurahan Klabulu yang terdiri dari dua kepala keluarga $(\mathrm{KK})$, sehingga mengakibatkan kebutuhan ekonomi meningkat serta jumlah produksi sampah rumah tangga menjadi banyak. Kelurahan Klabulu juga merupakan daerah rawan banjir. Selain itu, di Kelurahan Klabulu ada masyarakat menjadikan lahan kosong ataupun pinggiran jalan sebagai tempat pembuangan sampah. Jika tidak ada truk pengangkut sampah yang lewat di area itu, maka ketika musim hujan sampah akan terbawa air dan masuk ke dalam selokan mengakibatkan banjir karena drainase yang tidak lancar. Sehingga diperlukan kesadaran masyarakat tentang penanganan sampah yang baik dan benar agar dampak yang ditimbulkan dari dampak negatif sampah dapat diminimalisir.

\section{Tujuan Penelitian}

Tujuan penelitian ini adalah untuk mengetahui hubungan pengetahuan, keadaan sosial ekonomi dan tindakan penanganan sampah rumah tangga di RT 01/RW 05 Kelurahan Klabulu Kota Sorong.

\section{METODE}

Jenis penelitian ini adalah kuantitatif dengan rancangan cross sectional study. Penelitian dilakukan di RT 01/RW 05 Kelurahan Klabulu, Kota Sorong pada bulan Juli-Agustus tahun 2020. Populasi penelitian berjumlah 50 kepala keluarga. Sampel dalam penelitian ini adalah kepala keluarga yang tinggal di RT 01/RW 05 sebanyak 50 orang yang diambil secara total sampling. Instrumen penelitian menggunakan kuesioner. Data dianalisis menggunakan uji Chi-square dengan tingkat kepercayaan 0,05 .

\section{HASIL}

Tabel 1. Distribusi frekuensi karakteristik responden di RT 01/RW 05 Kelurahan Klabulu Kota Sorong

\begin{tabular}{|c|c|c|c|}
\hline No. & \multicolumn{1}{|c|}{ Karakteristik } & Frekuensi (f) & Persentase (\%) \\
\hline 1 & Umur & & 16,0 \\
\hline & $26-35$ Tahun & 19 & 38,0 \\
\hline & 36-45 Tahun & 16 & 32,0 \\
\hline & 46-55 Tahun & 7 & 14,0 \\
\hline & $56-65$ Tahun & & 88,0 \\
\hline 2 & Jenis Kelamin & 44 & 12,0 \\
\hline & Laki-Laki & 6 & 6,0 \\
\hline & Perempuan & 3 & 16,0 \\
\hline 3 & Pendidikan Terakhir & 8 & 20,0 \\
\hline & Tidak Sekolah/Tidak Lulus SD & 10 & 52,0 \\
\hline & Lulus SD & 26 & 6,0 \\
\hline & Lulus SLTP/SMP & 3 & \\
\hline & Lulus SLTA/SMA & & \\
\hline & Akademi/Perguruan Tinggi & & \\
\hline
\end{tabular}


Tabel 1 menunjukkan bahwa karakteristik responden paling banyak dengan umur 36-45 tahun sebanyak 19 responden (38,0\%), jenis kelamin laki-laki lebih banyak yakni berjumlah 44 responden $(88,0 \%)$, dan pendidikan terakhir lebih banyak dengan tingkat pendidikan lulus SLTA/SMA sebanyak 26 responden $(52,0 \%)$.

Tabel 2. Distribusi frekuensi responden menurut pengetahuan, keadaan sosial ekonomi, tindakan dan penanganan sampah rumah tangga di RT 01/RW 05 Kelurahan Klabulu Kota Sorong

\begin{tabular}{|c|l|c|c|}
\hline No. & \multicolumn{1}{|c|}{ Karakteristik } & Frekuensi (f) & Persentase (\%) \\
\hline 1 & Pengetahuan & & \\
\hline & Kurang & 28 & 56,0 \\
\hline & Baik & 22 & 44,0 \\
\hline 2 & Keadaan Sosial Ekonomi & 32 & 64,0 \\
\hline & Menengah & 18 & 36,0 \\
\hline & Tinggi & & 62,0 \\
\hline 3 & Tindakan & 31 & 38,0 \\
\hline$\quad$ Salah & 19 & \\
\hline & Benar & & 76,0 \\
\hline 4 & Penanganan Sampah Rumah Tangga & 38 & 24,0 \\
\hline & Ttidak memenuhi syarat & 12 & \\
\hline & Memenuhi syarat & & \\
\hline
\end{tabular}

Tabel 2 menunjukkan bahwa responden dengan pengetahuan kurang sebanyak 28 responden $(56,0 \%)$, keadaan sosial ekonomi menengah sebanyak 32 responden $(64,0 \%)$, tindakan salah sebanyak 31 responden $(62,0 \%)$, dan penanganan sampah rumah tangga yang tidak memenuhi syarat sebanyak 38 responden $(76,0 \%)$.

Tabel 3. Hubungan pengetahuan dengan penanganan sampah rumah tangga di RT 01/RW 08 Kelurahan Klabulu Kota Sorong

\begin{tabular}{|c|c|c|c|c|c|c|c|}
\hline \multirow{3}{*}{ No. } & \multirow{3}{*}{ Pengetahuan } & \multicolumn{4}{|c|}{ Penanganan Sampah Rumah Tangga } & \multirow{2}{*}{\multicolumn{2}{|c|}{ Total }} \\
\hline & & \multicolumn{2}{|c|}{$\begin{array}{l}\text { Tidak Memenuhi } \\
\text { Syarat }\end{array}$} & \multicolumn{2}{|c|}{ Memenuhi Syarat } & & \\
\hline & & $f$ & $\%$ & $f$ & $\%$ & $f$ & $\%$ \\
\hline 1 & Kurang & 18 & 64,3 & 10 & 35,7 & 28 & 100,0 \\
\hline \multirow[t]{3}{*}{2} & Baik & 20 & 90,9 & 2 & 9,1 & 22 & 100,0 \\
\hline & Total & 38 & 76,0 & 12 & 24,0 & 50 & 100,0 \\
\hline & & \multicolumn{4}{|c|}{$p$-value $=0,029$} & & $=0,05$ \\
\hline
\end{tabular}

Tabel 3 menunjukkan bahwa dari 28 responden yang berpengetahuan kurang tentang penanganan sampah rumah tangga yang tidak memenuhi syarat sebanyak 18 responden $(64,3 \%)$ dan yang memenuhi syarat sebanyak 10 responden (35,7\%). Responden yang berpengetahuan baik tentang penanganan sampah rumah tangga tidak memenuhi syarat sebanyak 20 responden $(90,9 \%)$ dan penanganan sampah rumah tangga yang memenuhi syarat sebanyak 2 responden $(9,1 \%)$ dari total 22 responden.

Hasil Chi-square diperoleh $p$-value $=0,029(p<0,05)$ maka $\mathrm{H}_{a}$ diterima yang artinya ada hubungan pengetahuan dengan penanganan sampah rumah tangga di RT 01/RW 08 Kelurahan Klabulu Kota Sorong.

Tabel 4. Hubungan keadaan sosial ekonomi dengan penanganan sampah rumah tangga di RT 01/RW 08 Kelurahan Klabulu Kota Sorong

\begin{tabular}{|c|c|c|c|c|c|c|c|}
\hline \multirow{3}{*}{ No. } & \multirow{3}{*}{$\begin{array}{c}\text { Keadaan Sosial } \\
\text { Ekonomi }\end{array}$} & \multicolumn{4}{|c|}{ Penanganan Sampah Rumah Tangga } & \multirow{2}{*}{\multicolumn{2}{|c|}{ Total }} \\
\hline & & \multicolumn{2}{|c|}{ Tidak Memenuhi Syarat } & \multicolumn{2}{|c|}{ Memenuhi Syarat } & & \\
\hline & & $f$ & $\%$ & $\mathrm{f}$ & $\%$ & $f$ & $\%$ \\
\hline 1 & Menengah & 21 & 65,6 & 11 & 34,4 & 32 & 100,0 \\
\hline \multirow[t]{3}{*}{2} & Tinggi & 17 & 94,4 & 1 & 5,6 & 18 & 100,0 \\
\hline & Total & 38 & 76,0 & 12 & 24,0 & 50 & 100,0 \\
\hline & & \multicolumn{4}{|c|}{$p$-value $=0,036$} & & $x=0,05$ \\
\hline
\end{tabular}


Tabel 4 menunjukkan bahwa dari 32 responden yang keadaan sosial ekonomi menengah tentang penanganan sampah rumah tangga yang tidak memenuhi syarat sebanyak 21 responden $(65,6 \%)$ dan yang memenuhi syarat sebanyak 11 responden (34,4\%). Keadaan sosial ekonomi tinggi tentang penanganan sampah rumah tangga tidak memenuhi syarat sebanyak 17 responden $(94,4 \%)$ dan penanganan sampah rumah tangga yang memenuhi syarat sebanyak 1 responden $(5,6 \%)$ dari total 18 responden.

Hasil fisher's exact test diperoleh $p$-value $=0,036(p<0,05)$ maka $\mathrm{H}_{\mathrm{a}}$ diterima yang artinya ada hubungan keadaan sosial ekonomi dengan penanganan sampah rumah tangga di RT 01/RW 08 Kelurahan Klabulu Kota Sorong.

Tabel 5. Hubungan tindakan dengan penanganan sampah rumah tangga di RT 01/RW 08 Kelurahan Klabulu Kota Sorong

\begin{tabular}{|c|c|c|c|c|c|c|c|}
\hline \multirow{3}{*}{ No. } & \multirow{3}{*}{ Tindakan } & \multicolumn{4}{|c|}{ Penanganan Sampah Rumah Tangga } & \multirow{2}{*}{\multicolumn{2}{|c|}{ Total }} \\
\hline & & \multicolumn{2}{|c|}{ Tidak Memenuhi Syarat } & \multicolumn{2}{|c|}{ Memenuhi Syarat } & & \\
\hline & & $f$ & $\%$ & $f$ & $\%$ & $f$ & $\%$ \\
\hline 1 & Salah & 29 & 93,5 & 2 & 6,5 & 31 & 100,0 \\
\hline \multirow[t]{3}{*}{2} & Benar & 9 & 47,4 & 10 & 52,6 & 19 & 100,0 \\
\hline & Total & 38 & 76,0 & 12 & 24,0 & 50 & 100,0 \\
\hline & & \multicolumn{4}{|c|}{$p$-value $=0,000$} & & $\alpha=0,05$ \\
\hline
\end{tabular}

Tabel 5 menunjukkan bahwa dari 31 responden yang tindakan salah tentang penanganan sampah rumah tangga yang tidak memenuhi syarat sebanyak 29 responden $(93,5 \%)$ dan yang memenuhi syarat sebanyak 2 responden (6,5\%). Tindakan benar tentang penanganan sampah rumah tangga tidak memenuhi syarat sebanyak 9 responden $(47,4 \%)$ dan penanganan sampah rumah tangga yang memenuhi syarat sebanyak 10 responden $(52,6 \%)$ dari total 19 responden.

Hasil fisher's exact test diperoleh $p$-value $=0,000(p<0,05)$ maka $\mathrm{H}_{a}$ diterima yang artinya ada hubungan tindakan dengan penanganan sampah rumah tangga di RT 01/RW 08 Kelurahan Klabulu Kota Sorong.

\section{PEMBAHASAN}

\section{Hubungan Pengetahuan Dengan Penanganan Sampah Rumah Tangga}

Berdasarkan hasil penelitian diketahui bahwa ada hubungan pengetahuan dengan penanganan sampah rumah tangga di RT 01/RW 05 Kelurahan Klabulu Kota Sorong. Ini dikarenakan semakin banyak tahu responden semakin baik penanganan sampah rumah tangganya sebaliknya semakin sedikit pengetahuannya semakin kurang penanganan sampah rumah tangganya.

Penelitian ini sejalan dengan penelitian terdahulu yang menunjukkan bahwa ada hubungan pengetahuan dengan perilaku penanganan sampah di Desa Tatung Kecamatan Balong Kabupaten Ponorogo karena dipengaruhi oleh beberapa hal yaitu tingkat pendidikan karena melalui pendidikan masyarakat mengetahui dan sadar akan bahaya sampah, dan hubungan sosial untuk bertukar informasi dalam kehidupan masyarakat ${ }^{(9)}$. Penelitian ini juga sesuai dengan penelitian lain yang menunjukkan bahwa adanya hubungan antara pengetahuan ibu rumah tangga dengan perilaku pengelolaan sampah pada ibu rumah tangga di Dusun Janti Kidul, Jatisarono, Nanggulan, Kulon Progo karena ibu rumah tangga kurang mendapatkan informasi/sosialisasi tentang pengelolaan sampah ${ }^{(10)}$.

Peneliti berasumsi bahwa pengetahuan kepala keluarga kurang dengan penanganan sampah rumah tangga tidak memenuhi syarat walaupun pendidikan terakhir kepala keluarga lebih banyak adalah lulus SLTA/SMA, hal ini disebabkan karena kurang mendapatkan sosialisasi/penyuluhan tentang penanganan sampah rumah tangga yang baik dan benar. Begitu juga pengetahuan baik dengan penanganan sampah rumah tangga yang tidak memenuhi syarat dikarenakan kurang adanya kesadaran dari kepala keluarga dalam penanganan sampah di tingkat rumah tangga sampai ke tempat pembuangan sementara (TPS), dan jarak rumah ke TPS cukup jauh sehingga masyarakat memilih membuangnya ke parit dan pinggir jalan.

\section{Hubungan Keadaan Sosial Ekonomi Dengan Penanganan Sampah Rumah Tangga}

Berdasarkan hasil penelitian diketahui bahwa ada hubungan keadaan sosial ekonomi dengan penanganan sampah rumah tangga di RT 01/RW 05 Kelurahan Klabulu Kota Sorong. Ini dikarenakan responden dengan tingkat sosial ekonomi yang rendah ataupun menengah belum mampu untuk 
memenuhi semua kebutuhan hidupnya termasuk untuk melakukan penanganan sampah. Sebaliknya responden dengan tingkat sosial ekonomi yang tinggi mampu untuk memenuhi semua kebutuhan hidup termasuk untuk melakukan penanganan sampah rumah tangga.

Penelitian ini sejalan dengan penelitian terdahulu yang menunjukkan bahwa variabel sosial ekonomi (pendidikan dan pendapatan) mempunyai pengaruh yang signifikan terhadap perilaku masyarakat dalam pengelolaan sampah di Kecamatan Ampana Kota Kabupaten Tojo Una-Una, hal ini karena dengan pendapatan penduduk yang sangat rendah tentu saja akan menghambat kemajuan pembangunan diantaranya kemajuan pendidikan masyarakatnya yang tentu saja akan berefek ke hal lain termasuk pemahaman dan kesadaran masyarakat dalam pengelolaan sampah(11). Penelitian ini juga sesuai dengan penelitian lain yang menunjukkan bahwa adanya pengaruh ekonomi (pendapatan) terhadap pengelolaan sampah rumah tangga di Kota Manado, karena semakin tinggi ekonomi masyarakat maka seharusnya akan semakin tinggi juga sikap pedulinya dalam pengelolaan sampah rumah tangga, dan semakin rendah ekonomi masyarakat maka akan semakin rendah pula sikap pedulinya dalam pengelolaan sampah rumah tangga ${ }^{(12)}$.

Peneliti berasumsi bahwa keadaan sosial ekonomi menengah dengan penanganan sampah rumah tangga yang tidak memenuhi syarat lebih banyak daripada yang memenuhi syarat, karena walaupun keadaan sosial ekonominya bisa dikatakan cukup belum tentu dalam penanganan sampah rumah tangganya baik pula. Begitu juga keadaan sosial ekonomi tinggi dengan penanganan sampah yang tidak memenuhi syarat lebih banyak dibandingkan yang memenuhi syarat, karena yang seharusnya keadaan sosial ekonomi tinggi itu lebih baik dalam penanganan sampah tetapi masih ada juga yang tidak memenuhi syarat. Hal ini disebabkan kurangnya kepedulian dan kesadaran dari kepala keluarga untuk melakukan penanganan sampah maka rumah tangga itu tidak akan melakukannya. Keputusan rumah tangga untuk melakukan penanganan sampah adalah didasari oleh rasa kepedulian terhadap lingkungan hidup dan kebiasaan rumah tangga itu sendiri.

\section{Hubungan Tindakan Dengan Penanganan Aampah Rumah Tangga}

Berdasarkan hasil penelitian didapatkan bahwa ada hubungan tindakan dengan penanganan sampah rumah tangga di RT 01/RW 05 Kelurahan Klabulu Kota Sorong. Ini dikarenakan tidak TPS yang berada di lingkungan tersebut, sehingga responden langsung membuang sampah sembarangan seperti ke parit, lahan kosong, dan belakang rumah.

Penelitian ini sejalan dengan penelitian terdahulu yang menunjukkan bahwa ada hubungan antara tindakan dengan pengelolaan sampah, hal ini dikarenakan adanya rasa yang tidak peduli terhadap lingkungan seperti membuat kerajinan dari barang bekas dan mendaur ulang sampah organik menjadi pupuk kompos sehingga sampah menjadi terkelola dengan baik, maka dari itu hendaklah petugas kesehatan selalu mendampingi masyarakat dalam mengelola sampah dengan benar dan dapat dipergunakan lagi ${ }^{(13)}$. Penelitian ini juga sesuai dengan penelitian lain yang menunjukkan bahwa ada hubungan antara tindakan dengan pengelolaan sampah di Kelurahan Sanua Kecamatan Kendari Barat Kota Kendari Tahun 2018, hal ini disebabkan karena masih minimnya kesadaran responden akan pemanfaatan sampah dan pembuangan sampah yang tidak dikelola dengan baik, sehingga masih ada responden yang bahkan tidak peduli dengan sampah yang berserakan ${ }^{(14)}$.

Peneliti berasumsi bahwa tindakan dalam penanganan sampah rumah tangga di RT 01/RW 05 Kelurahan Klabulu masih perlu diperbaiki, dikarenakan masih banyak kepala keluarga yang tidak memenuhi syarat dalam melakukan penanganan sampah rumah tangga. Juga kurang adanya kesadaran dan peduli membuang sampah di TPS. Banyak faktor pendukung atau suatu kondisi memungkinkan tindakan kepala keluarga antara lain ialah ketersediaan sarana TPS, untuk terwujudnya sikap agar menjadi suatu perbuatan nyata diperlukan faktor pendukungmatau suatu kondisi memungkinkan untuk menciptakan lingkungan yang bersih dan sehat.

\section{KESIMPULAN}

Kesimpulan penelitian ini adalah ada hubungan pengetahuan, keadaan sosial ekonomi dan tindakan dengan penanganan sampah rumah tangga di RT 01/RW 05 Kelurahan Klabulu Kota Sorong. Disarankan kepada kepala keluarga dapat membuat kebiasaan dengan membuang sampah ke TPS. Selain itu, kepada pihak Kelurahan Klabulu diharapkan dapat berkolaborasi dengan tokoh masyarakat dan petugas kesehatan agar memberikan sosialisasi atau penyuluhan melalui komunikasi langsung kepada kepala keluarga. Kemudian kepada pihak Dinas Perumahan dan Kawasan Pemukiman Kota Sorong dapat memberikan pelatihan tentang penanganan sampah rumah tangga yang memenuhi syarat serta memberikan fasilitasi sarana seperti tempat sampah dan ketersediaan TPS, memasang 
spanduk larangan membuang sampah, poster-poster larangan membuang sampah dan membagikan booklet Peraturan Daerah Kota Sorong tentang Pengelolaan Persampahan.

\section{DAFTAR PUSTAKA}

1. Ahmad, N., Yuantari C. Faktor-Faktor Yang Mempengaruhi Pengelolaan Sampah Rumah Tangga Di Perumahan Bukit Permata Puri Kelurahan Beringin Kecamatan Ngaliyan Kota Semarang Tahun 2015. Artikel Ilmiah. Fakultas Kesehatan. Universitas Dian Nuswantoro; 2015.

2. Hasbullah, T., Nurmaini. Analisis Pengelolaan Sampah Di Kota Subulussalam, Tahun 2017. Jurnal Jumantik. 2019; 4(2):135-146.

3. Sanubari, R. Respon Amerika Serikat Terhadap Kebijakan Larangan Impor Sampah Daur Ulang Tiongkok. Jurnal Departemen Hubungan Internasional. 2019;5(1):36-49.

4. The World Bank. What a Waste (A Global Snapshot of Solid Waste Management to 2050). 2016 [Diakses, 26 Mei 2020]. http://datatopics.worldbank.org/what-a-waste/.

5. Kementerian Lingkungan Hidup dan Kehutanan (KLHK). Paparan Sistem Informasi Pengelolaan Sampah Nasional. Jakarta; 2019.

6. Dinas Perumahan dan Kawasan Pemukiman. Paparan Informasi Persampahan Kota Sorong. Kota Sorong; 2017.

7. Indartik, E., Deden D., Pribadi M. Penanganan Sampah Rumah Tangga Di Kota Bandung: Nilai Tambah Dan Potensi Ekonomi. Jurnal Penelitian Sosial dan Ekonomi Kehutanan. 2018;15(3):195211.

8. Mulasari, S., Husodo A., Muhadjir N. Analisis Situasi Permasalahan Sampah Kota Yogyakarta Dan Kebijakan Penanggulangannya. Jurnal Kesehatan Masyarakat. 2016;11 (02):96-106.

9. Eka, N. Faktor-Faktor Yang Berhubungan Dengan Perilaku Penanganan Sampah Rumah Tangga Di Desa Tatung Kecamatan Balong Kabupaten Ponorogo. Skripsi. Program Studi S1 Kesehatan Masyarakat. Stikes Bhakti Husada Mulia Madiun; 2019.

10.Zunianto, R. Faktor-Faktor Yang Mempengaruhi Perilaku Pengelolaan Sampah Pada lbu Rumah Tangga Di Dusun Janti Kidul, Jatisarono, Nanggulan, Kulon Progo. Jurnal Kesehatan Lingkungan. 2019;5(3):50-57.

11.Hardi, H., Rosida P., Bachri S. Pengaruh Sosial Ekonomi, Sarana Dan Prasarana Terhadap Perilaku Masyarakat Dalam Pengelolaan Sampah Di Kecamatan Ampana Kota Kabupaten Tojo Una-Una. Jurnal Katalogis. 2017;5(9):145-150.

12.Gobel, L. Analisis Faktor Sosial Ekonomi Yang Mempengaruhi Pengelolaab Sampah Rumah Tangga Di Kota Manado (Studi Kasus Kecamata Malalayang). Jurnal Berkala Ilmiah Efisiensi. 2020;20(1):94-103.

13.Wildawati, D. Faktor Yang Berhubungan Dengan Pengelolaan Sampah Rumah Tangga Berbasis Masyarakat Di Kawasan Bank Sampah Hanasty Kota Solok. Jurnal Human Care. 2019;4(3):149158.

14.Rachman, R. Faktor-Faktor Yang Berhubungan Dengan Pengelolaan Sampah Rumah Tangga Di Kelurahan Sanua Kota Kendari Tahun 2018. Jurnal IImiah Teknik Sipil. 2020;8(1):37-50. 